\title{
Prevalence of Obstructive Sleep Apnea in Orthodontic Patients with Different Skeletal Classes Using STOP-BANG Questionnaire: An Observational Study
}

\author{
Hany A. Ghonim*, Essam M. Nassef, Fouad A. El Sharaby \\ Department of Orthodontics and Dentofacial Orthopedics, Faculty of Dentistry, Future University in Egypt, Cairo, Egypt.
}

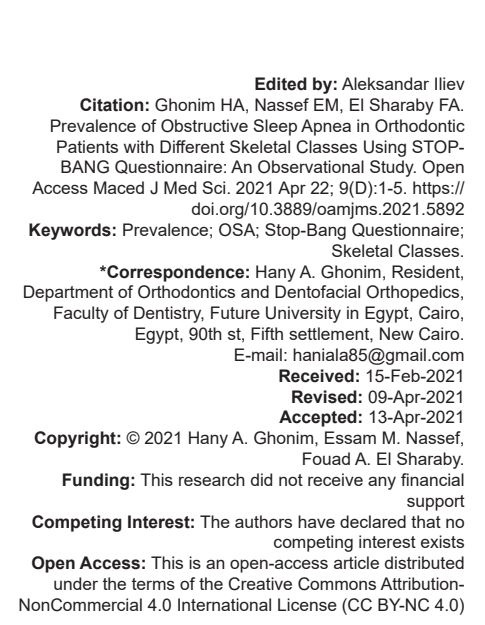

\section{Abstract}

AIM: The aim of the study was to determine the prevalence of obstructive sleep apnea (OSA) in orthodontic adult patients with different skeletal classes and no pathology in the airway as detected from the lateral cephalometric radiographs using the STOP-BANG questionnaire.

METHODS: The sample comprised 309 subjects (152 males and 157 females) collected from the Egyptian population presented to the orthodontic follicular unit extraction for treatment. The sample was divided into three groups based on the anteroposterior relationship between maxilla and mandible (ANB angle) as evident from pretreatment latera cephalometric. Patients were asked to fill out general medical history, sign a consent form, and fill in the STOPBANG questionnaire. Patient's neck size and height were measured using tape measuring tool and weighing scale, respectively. Body mass index (BMI) was obtained. After submission of the questionnaire, scores were measured for each patient to evaluate the severity of OSA

RESULTS: Comparison between OSA risk in the three classes showed no statistically significant difference $(p=0.791$, effect size $=0.052)$.

CONCLUSIONS: STOP-BANG questionnaire showed that there was no statistically significant difference in the prevalence of OSA between different skeletal classes.

\section{Introduction}

Sleep apnea is a common disorder in which one or more pauses in breathing or shallow breaths are encountered during sleep [1]. Obstructive sleep apnea (OSA) is the most common type of sleep apnea where the upper airway could become blocked due to: Too much muscles relaxation during sleep or the weight of neck narrowing the airway [2].

Sleep apnea can affect anyone at any age [2]. Risk factors for sleep apnea include: Being male, overweight, over 40 years, having a large neck size (17 inches or greater in men and 16 inches or greater in women), having large tonsils, a large tongue, or a small jaw bone as well as having a family history of OSA [3].

The STOP-BANG questionnaire is a scoring model consisting of easily administered eight questions starting with the acronym STOP-BANG and its scores were based on YES/NO answers (score 1/8). Questions were related to the clinical features of sleep apnea (snoring, tiredness, observed apnea, high blood pressure, BMI, age, neck circumference, and gender). This tool can assess if the patient is low, moderate, or high risk group for OSA [4].

The aim of the current study was to determine the prevalence of OSA in orthodontic adult patients with different skeletal classes.

\section{Materials and Methods}

The current observational, cross-sectional, and prevalence study was performed in the outpatient clinic of the Orthodontic Department in the Faculty of Oral and Dental Medicine of the Future University in Egypt. The study was approved by the Ethical Committee of the Future University. The recruited sample was 309 subjects (152 males and 157 females) collected from the Egyptian population presenting to the clinic for orthodontic treatment. 
The eligibility criteria included; adult male and female orthodontic patients (from 18 to 60 years old) with no pathology in the airway as detected from radiograph. Subjects with systematic diseases (heart disease, renal disease liver disease, and diabetes), with medications as sedative drugs, with enlarged adenoid, with development anomalies (e.g., micrognathia), smoking, and alcohol consumption where excluded from the study.

Records including radiographs, photographs, and study models were collected for each subject. Based on the skeletal pattern as verified from the lateral cephalometric radiograph, the sample was divided into three groups. Group I comprised skeletally class 1 patients with an ANB angle between $\left(0^{\circ}\right.$ and $\left.4^{\circ}\right)$, group II skeletally class 2 patients with ANB angle $\left(>4^{\circ}\right)$, while group III comprised skeletally class 3 patients with an ANB angle $\left(<0^{\circ}\right)$.

STOP-BANG questionnaire (Figure 1) was distributed on the orthodontic patients who were enrolled into the study. The collected lateral cephalometric images (Sirona Dental Systems Gmbh, Bensheim, Germany) obtained for each patient were imported into the Anatomage software (Anatomage InVivoDental 5, CA, USA) and saved as Digital Imaging and Communications in medical imaging format.

\begin{tabular}{|c|c|c|}
\hline$\square$ Yes & $\square$ No & $\begin{array}{l}\text { Snoring? } \\
\text { Do you Snore Loudly (Loud enough } \\
\text { to be heard through closed doors } \\
\text { or your bed-partner elbows you for } \\
\text { snoring at night) }\end{array}$ \\
\hline$\square$ Yes & $\square \mathrm{No}$ & $\begin{array}{l}\text { Tired? } \\
\text { Do you often feel Tired, Fatigued, } \\
\text { or Sleepy during the daytime (tired } \\
\text { enough that you could fall asleep } \\
\text { while driving?) }\end{array}$ \\
\hline$\square$ Yes & $\square$ No & $\begin{array}{l}\text { Observed? } \\
\text { as anyone observed you Stop } \\
\text { Breathing or Choking/Gasping } \\
\text { during your sleep? }\end{array}$ \\
\hline$\square$ Yes & $\square$ No & $\begin{array}{l}\text { Pressure? } \\
\text { Do you have or are you being } \\
\text { treated for High Blood Pressure? }\end{array}$ \\
\hline$\square$ Yes & $\square$ No & Body Mass Index more than $35 \mathrm{~kg} / \mathrm{m}^{2}$ \\
\hline$\square$ Yes & $\square$ No & Age Older than 50 years old? \\
\hline$\square$ Yes & $\square \mathrm{No}$ & $\begin{array}{l}\text { Neck size: Is it large? (Measured } \\
\text { around Adam's apple) For Male, is } \\
\text { your shirt collar } 17 \text { inches } / 43 \mathrm{~cm} \\
\text { or larger? For Female, is your shirt } \\
\text { collar } 16 \text { inches } / 41 \mathrm{~cm} \text { or larger? } \\
\text { Gender: Male? }\end{array}$ \\
\hline
\end{tabular}

Figure 1: STOP-BANG questionnaire used in the study

Anatomical landmarks, planes, and angels (Table 1) for cephalometric analysis were identified by the main author $(\mathrm{HG})$ twice at two different occasions and one more time by the co-author (Figure 2). Analysis was performed according to Steiner [5].
Patient's neck size and height were measured using tape measuring tool (RZFIT, Shandong, China) and patients' weight measured by weighing scale (Beurer $\mathrm{GmbH}$, Ulm, Germany). Body mass index (BMI) was obtained by the formula $\mathrm{BMI}=\mathrm{kg} / \mathrm{m}^{2}$ where $(\mathrm{kg})$ is a person's weight in kilograms and $\left(\mathrm{m}^{2}\right)$ is their height in meters squared. After submission of the questionnaire, scores were measured for each patient to evaluate the severity of OSA

Table 1: Definitions of anatomical landmarks, planes, and angles on the lateral cephalometric

\begin{tabular}{ll}
\hline A point (A) & The point of the deepest concavity anteriorly on the maxillary alveolus \\
B point (B) & The point of the deepest concavity anteriorly on the mandibular symphysis \\
Sella (S) & The midpoint of the sella turcica (pituitary fossa) \\
Nasion (N) & The most anterior point on the frontonasal suture \\
SN line & $\begin{array}{l}\text { The plane demonstrated by a line through the nasion and sella } \\
\text { SNA }\end{array}$ \\
$\begin{array}{l}\text { This angle represents the relative anterioposterior position of the maxilla } \\
\text { to the cranial base }\end{array}$ \\
SNB & $\begin{array}{l}\text { This angle represents the relative anterioposterior position of the mandible } \\
\text { to the cranial base }\end{array}$ \\
ANB & $\begin{array}{l}\text { This angle represents the relative anterioposterior position of the maxilla } \\
\text { to the mandible and can be used to determine skeletal classes }\end{array}$ \\
\end{tabular}

Patients with a STOP-Bang score of $0-2$ were classified as being at low risk for OSA. Those with a STOP-Bang score of 3-4 were classified as being a moderate risk for OSA, while patients with a score of 5-8 were classified of being at high or severe risk for OSA.

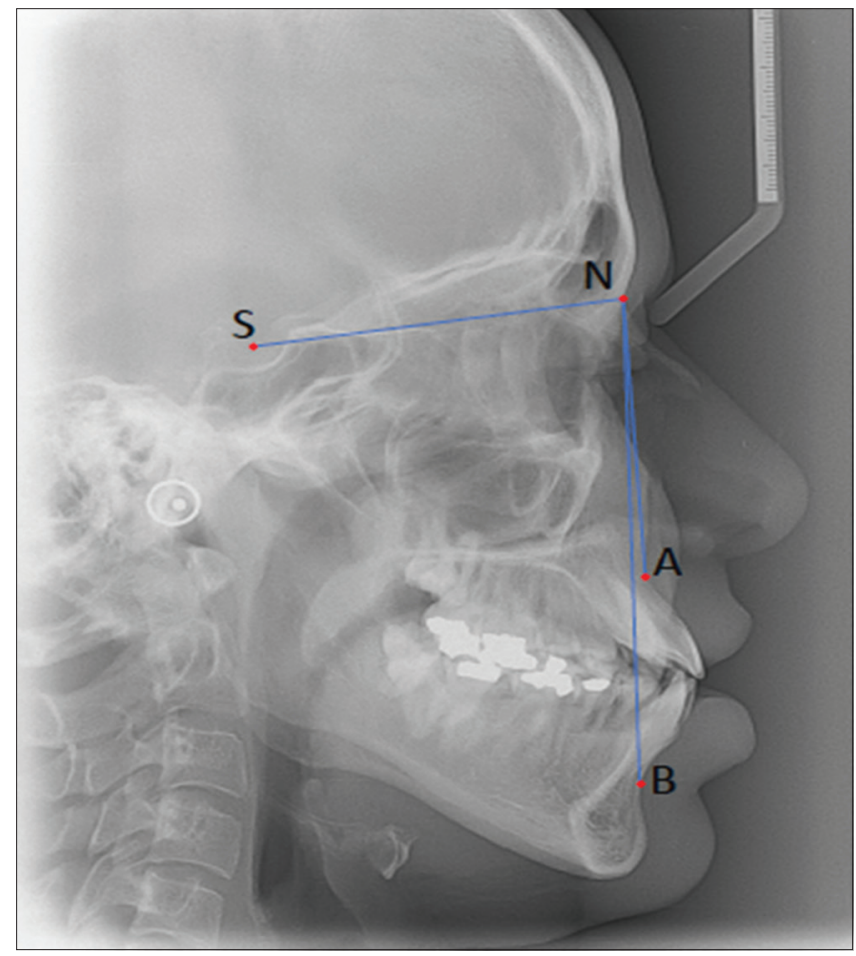

Figure 2: Anatomical landmarks, planes, and angles

\section{Statistical analysis}

Statistical analysis was performed with IBM SPSS Statistics for Windows, Version 23.0. Armonk, NY: IBM Corp. Qualitative data were presented as frequencies and percentages. Chi-square was used to compare between the three classes. Numerical data were explored for normality by checking the distribution 
of data and using tests of normality (KolmogorovSmirnov and Shapiro-Wilk tests). Data showed non-parametric distribution. Numerical data were presented as mean, standard deviation (SD), median, and range values. Kruskal-Wallis test was used to compare between the three classes. Dunn's test was used for pair-wise comparisons when Kruskal-Wallis test is significant. The significance level was set at $p \leq 0.05$

\section{Results}

\section{Demographic data}

The present study was conducted on 309 subjects; 152 males (49.2\%) and 157 females (50.8\%). They were also classified according to their ANB angle into: Skeletal class I patients (152 subjects), skeletal class II patients (96 subjects), and skeletal class III patients (61 subjects). The mean (SD) values of age were $39.5( \pm 14.5)$ years old with a minimum of 20 and a maximum of 50 years old.

\section{Prevalence of OSA according to STOP-BANG questionnaire (Tables 2 and 3 and Figures 3 and 4)}

The overall prevalence of subjects with low risk of OSA was $49.2 \%$, intermediate risk was $31.1 \%$, and high risk was $19.7 \%$ (Figure 3).

Table 2: Frequencies and percentages of OSA risk assessment in different classes

\begin{tabular}{|c|c|c|c|c|c|c|c|c|}
\hline \multirow[t]{2}{*}{ OSA risk } & \multicolumn{2}{|c|}{$\begin{array}{l}\text { Skeletal class } \\
\text { I }(\mathrm{n}=152)\end{array}$} & \multicolumn{2}{|c|}{$\begin{array}{l}\text { Skeletal class } \\
\text { II }(\mathrm{n}=96)\end{array}$} & \multicolumn{2}{|c|}{$\begin{array}{l}\text { Skeletal class } \\
\text { III }(n=61)\end{array}$} & \multicolumn{2}{|c|}{ Total } \\
\hline & $\mathrm{n}$ & $\%$ & $\mathrm{n}$ & $\%$ & $\mathrm{n}$ & $\%$ & $\mathrm{n}$ & $\%$ \\
\hline Low risk & 111 & 73 & 72 & 75 & 41 & 67.2 & 224 & 72.5 \\
\hline Intermediate risk & 32 & 21.1 & 18 & 18.8 & 14 & 23 & 64 & 20.7 \\
\hline High risk & 9 & 5.9 & 6 & 6.2 & 6 & 9.8 & 21 & 6.8 \\
\hline Total & 152 & 100 & 96 & 100 & 61 & 100 & 309 & 100 \\
\hline
\end{tabular}

Distribution of low, intermediate, and high risk of OSA subjects according to different classes is presented in Table 2 and Figure 4. Patients at low risk for OSA were 111 subjects $(73 \%)$ in skeletal class I group, 72 subjects $(75 \%)$ in skeletal class II group, and 224 subjects $(72.5 \%)$ in skeletal class III group.

Table 3: Frequencies, percentages, and results of Chi-square test for comparison between OSA risk assessment in different classes

\begin{tabular}{|c|c|c|c|c|c|c|c|c|}
\hline \multirow[t]{2}{*}{ OSA risk } & \multicolumn{2}{|c|}{$\begin{array}{l}\text { Skeletal class I } \\
(\mathrm{n}=152)\end{array}$} & \multicolumn{2}{|c|}{$\begin{array}{l}\text { Skeletal class II } \\
(\mathrm{n}=96)\end{array}$} & \multicolumn{2}{|c|}{$\begin{array}{l}\text { Skeletal class } \\
\text { III }(n=61)\end{array}$} & \multirow[t]{2}{*}{$\mathrm{p}$-value } & \multirow[t]{2}{*}{$\begin{array}{l}\text { Effect } \\
\text { size (v) }\end{array}$} \\
\hline & $\mathrm{n}$ & $\%$ & $\mathrm{n}$ & $\%$ & $\mathrm{n}$ & $\%$ & & \\
\hline Low risk & 111 & 73 & 72 & 75 & 41 & 67.2 & 0.791 & 0.052 \\
\hline Intermediate risk & 32 & 21.1 & 18 & 18.8 & 14 & 23 & & \\
\hline High risk & 9 & 5.9 & 6 & 6.3 & 6 & 9.8 & & \\
\hline
\end{tabular}

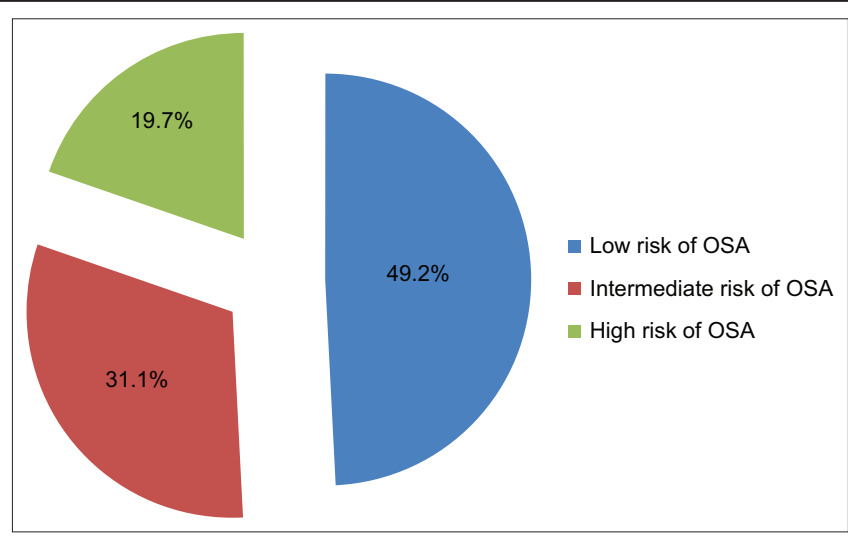

Figure 3: Pie chart representing overall prevalence of obstructive sleep apnea

Patients at intermediate risk for OSA were 32 subjects $(21.1 \%)$ in skeletal class I group, 18 subjects $(18.8 \%)$ in skeletal class II group, and 14 subjects (23\%) in skeletal class III group.

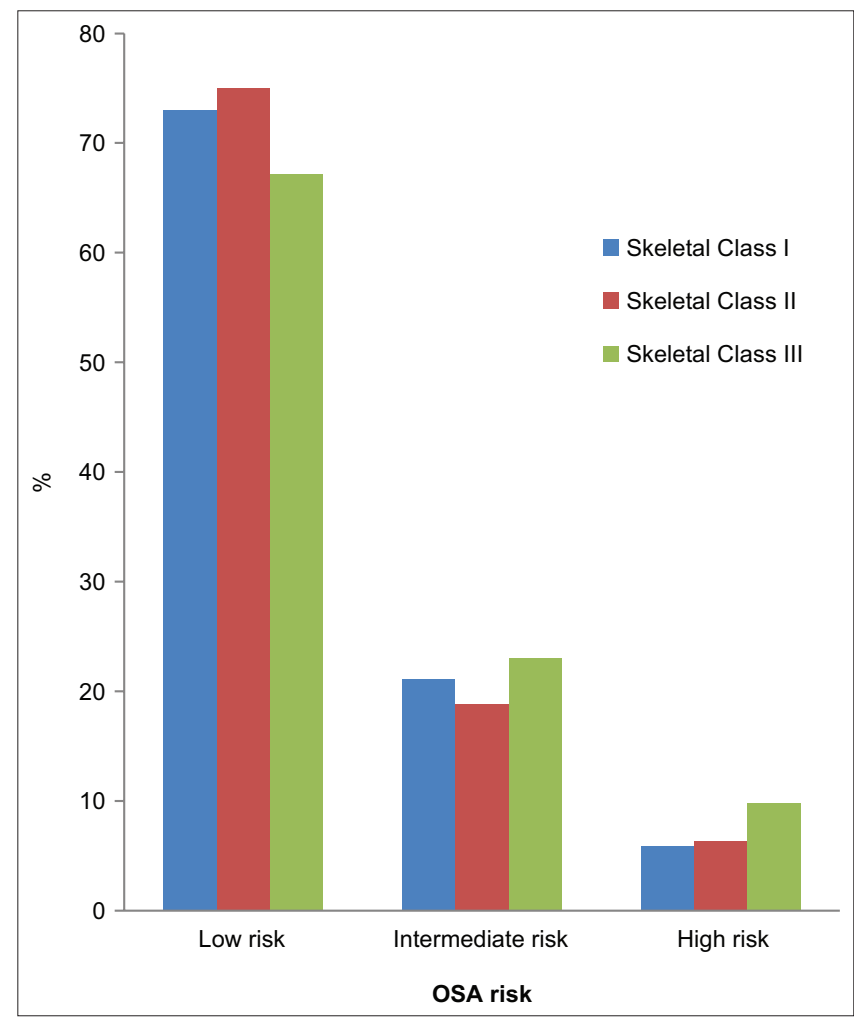

Figure 4: Bar chart representing prevalence of obstructive sleep apnea risk among different classes

Patients at high risk for OSA were 9 subjects $(5.9 \%)$ in skeletal class I group, 6 subjects $(6.2 \%)$ in skeletal class III group, and 6 subjects $(9.8 \%)$ in skeletal class III group.

Comparison between OSA risk in the three classes showed that there was no statistically significant difference between the three classes $(p=$ 0.791 , effect size $=0.052$ ). No significant difference was found between inter- and intra-observer variability. 


\section{Discussion}

OSA has been defined as a potentially life threatening condition [6], in which there is a periodic cessation of breathing. OSA exhibits a prevalence of $2 \%$ in the adult female population and $4 \%$ in the adult male population [7].

There are many predisposing factors for OSA such as obesity, upper airway obstruction, alcohol consumption, smoking, sedative drugs, and certain developmental anomalies such as micrognathia, retrognathia, enlarged adenoids, tongue, and tonsils [3]. In addition, a high predilection is seen in old age and males [8].

Signs and symptoms of OSA include snoring, choking, increased body movements, restlessness during sleep, bruxism, growth failure restriction, mouth breathing leading to xerostomia, chronic nasal congestion, sleep walking, obesity, fatigue, irritability, frustration, depression, anxiety, aggression, hyperactivity, poor school performance, poor concentration, and distraction [9].

There are many people with sleep apnea who have not been diagnosed or received treatment. The Apnea-Hypopnea Index (AHI) is an index used to indicate the severity of sleep apnea. It is represented by the number of apnea and hypopnea events per hour of sleep. The apneas (pauses in breathing) must last for at least $10 \mathrm{~s}$ and be associated with a decrease in blood oxygenation. Based on the AHI, Korkalainen et al. [10] classified patients into four severity groups: Non-OSA $(\mathrm{AHI}<5)$; mild $(5 \leq \mathrm{AHI}<15)$; moderate $(15 \leq \mathrm{AHI}<30)$; and severe OSA $(\mathrm{AHI} \geq 30)$.

The gold standard for diagnosis of OSA is attended polysomnography (PSG) which involves collection of seven or more data channels, including electroencephalogram and electroencephalogram for sleep staging, electromyogram, electrocardiogram, and respiratory channels [11]. PSG is expensive and not available everywhere [12].

There are other methods to diagnose OSA such as lateral cephalograms, magnetic resonance imaging, cone beam computed tomography, and questionnaires. Several studies advocate lateral cephalograms to evaluate the upper airway. Although this method has been widely used, a two-dimensional projection of a three-dimensional anatomical structure is questionable as it has many drawbacks such as severe limitations with the inherent errors of a two dimensional representation of a three dimensional structure being distortion, differences in magnifications, superimposition of the bilateral craniofacial structures, and in addition, a low reproducibility as a result of difficulties in landmark identification and the lack of information about crosssectional area and volume [13].

As a result of its ease of use, efficiency, and high sensitivity, The STOP-Bang questionnaire has been widely adopted and validated in various populations and among patients with assorted medical conditions according to Nagappa et al. [4]

OSA screening questionnaires are used for predicting OSA in sleep clinics or in general population because of the unavailability and time-consuming nature and cost of PSG. There are three main commonly used questionnaires that help orthodontists' to diagnosis or predict if the patient has OSA or not which is Epworth Sleepiness Scale (ESS), Berlin (BQ), and Stop-Bang questionnaire. Amra et al. [14] compared the three questionnaires for diagnosing OSA and he concluded that $B Q$ and STOP-Bang are more sensitive and accurate than ESS for OSA screening. Chung et al. [15] found that the probability of moderate to severe OSA increases in direct proportion to the STOP-Bang score, which makes the questionnaire an easily used tool for identifying patients at high risk for OSA.

Based upon the above facts, and by considering the existence of discrepancies in relation to pharyngeal airway (upper) and malocclusion form, it was decided to do an epidemiological, questionnaire, descriptive, cross-sectional, and observational study to determine the prevalence of OSA in different malocclusion using STOP-BANG questionnaire and compare the pharyngeal airway of patients in Class I, Class II, and Class III skeletal pattern.

The results of the study showed that there was no significant difference between the three classes according to STOP-BANG questionnaire. The overall prevalence of subjects with low risk of OSA was $49.2 \%$, intermediate risk was $31.1 \%$, and high risk was $19.7 \%$ while Chung et al. [10] concluded that OSA was present in $68.4 \%$ with $29.9 \%$ mild, $20.5 \%$ moderate, and $18.0 \%$ severe OSA with median age which was 60 years compared to median age of 39.5 years in this study.

The results of the study also showed that the percentage of high risk patients for OSA was greater in male subjects than female and that was the same results as Assal and Kamal [16].

Bixler et al. [17] concluded that the prevalence of sleep apnea tends to increase with age but the clinical significance (severity) of apnea decreases, while in this study there was no statistically significant difference between subjects with age $\leq 50$ years and subjects with age $>50$ years at high risk to OSA according to the STOP-BANG questionnaire. Bixler et al. used polysmnography and $\mathrm{AHI}$ to diagnosis OSA which need to sleep one night at the sleep center, while in this study questionnaire was used which is an easy and reliable tool to diagnose OSA.

The results of the study showed that there was no statistically significant difference regarding BMI groups across the OSA risk groups. Wosu et al. [18] found that there was a strong positive association of high risk for OSA with obesity. However, Wosu et al. 
defined obesity as patients with $\mathrm{BMI} \geq 30 \mathrm{~kg} / \mathrm{m}^{2}$, while in this study patient with $\mathrm{BMI} \geq 35 \mathrm{~kg} / \mathrm{m}^{2}$ considered obese.

Veloro et al. [19] measured the neck size and noted the data from PSG to 149 males and found that the high probability of having true OSA in symptomatic male adults with a collar size $\geq 40 \mathrm{~cm}$, definitive management may be required for those patients, while those with a collar size $<40 \mathrm{~cm}$ may need to undergo further confirmatory tests.

Paul et al. [20] suggested that there was a strong relationship between the airway and skeletal classes showing a less airway in class II patients with high ANB, while in this study the results showed that there were no significant differences between median total volumes, minimum area, lateral, as well AP dimensions of airway between different skeletal classes.

\section{Conclusions}

According to the results aforementioned, the OSA was found not to be affected by the skeletal class of the patients. Moreover, STOP-BANG questionnaire was a sufficient and simple tool to diagnose OSA.

\section{References}

1. Laratta CR, Ayas NT, Povitz M, Pendharkar SR. Diagnosis and treatment of obstructive sleep apnea in adults. CMAJ. 2017;189(48):E1481-8. https://doi.org/10.1503/cmaj.170296 PMid:29203617

2. Ho ML, Brass SD. Obstructive sleep apnea. Neurol Int. 2011;3(3):e15. PMid:22368774

3. Spicuzza L, Caruso D, di Maria G. Obstructive sleep apnoea syndrome and its management. Ther Adv Chronic Dis. 2015;6(5):273-85. https://doi.org/10.1177/2040622315590318 PMid:26336596

4. Nagappa M, Liao P, Wong J, Auckley D, Ramachandran SK, Memtsoudis S, et al. Validation of the STOP-bang questionnaire as a screening tool for obstructive sleep apnea among different populations: A systematic review and meta-analysis. PLoS One. 2015;10(12):e0143697. https://doi.org/10.1371/journal.pone.0143697 PMid:26658438

5. Steiner CC. Cephalometrics for you and me. Am J Orthod Dentofacial Orthop. 1953;39(10):729-55.

6. Jayaraman $\mathrm{G}$, Sharafkhaneh $\mathrm{H}$, Hirshkowitz M, Sharafkhaneh A Pharmacotherapyofobstructivesleepapnea. TherAdvRespirDis.
2008;2(6):375-86. https://doi.org/10.1177/1753465808098225 PMid:19124383

7. Bronoosh P, Khojastepour L. Analysis of pharyngeal airway using lateral cephalogram vs CBCT images: A crosssectional retrospective study. Open Dent J. 2015;9:2636. https://doi.org/10.2174/1874210601509010263 PMid:26464593

8. Ulfberg J, Carter $\mathrm{N}$, Talbäck $\mathrm{M}$, Edling $\mathrm{C}$ Headache, snoring and sleep apnoea. J Neurol. 1996;243(9):621-5. $\quad$ https://doi.org/10.1007/bf00878656 PMid:8892061

9. Bailey DR. Oral evaluation and upper airway anatomy associated with snoring and obstructive sleep apnea. Dent Clin North Am. 2001;45(4):715-32. PMid:11699238

10. Korkalainen $H$, Töyräs $J$, Nikkonen $S$, Leppänen $T$. Mortality-risk-based apnea-hypopnea index thresholds for diagnostics of obstructive sleep apnea. J Sleep Res. 2019;28(6):e12855. https://doi.org/10.1111/jsr.12855 PMid:30941829

11. Fleetham J, Ayas N, Bradley D, Fitzpatrick M, Oliver TK, Morrison D, etal. Canadianthoracicsociety 2011 guideline update: Diagnosis and treatment of sleep disordered breathing. Can Respir J. 2011;18(1):25-47. https://doi.org/10.1155/2011/506189 PMid:21369547

12. Kumar, Mohan V, Mallick HN, Shrivastava D. Demand for Affordable Sleep Study; 2018. p. 101-2.

13. Ogawa T, Enciso R, Shintaku WH, Clark GT. Evaluation of cross-section airway configuration of obstructive sleep apnea. Oral Surg Oral Med Oral Pathol Oral Radiol Endodontol. 2007;103(1):102-8. https://doi.org/10.1016/j.tripleo.2006.06.008 PMid:17178502

14. Amra B, Javani $M$, Soltaninejad $F$, Penzel T, Fietze I, Schoebel C, et al. Comparison of Berlin questionnaire, STOP-bang, and Epworth sleepiness scale for diagnosing obstructive sleep apnea in Persian patients. Int J Prev Med. 2018;9:28. https://doi.org/10.4103/ijpvm.ijpvm_131_17 PMid:29619152

15. Chung F, Abdullah HR, Liao P. STOP-bang questionnaire: A practical approach to screen for obstructive sleep apnea. Chest. 2016;149(3):631-8. https://doi.org/10.1378/chest.15-0903 PMid:26378880

16. Assal HH, Kamal E. Gender differences in polysomnographic findings in Egyptian patients with obstructive sleep apnea syndrome. Egypt J Chest Dis Tuberc. 2016;65(3):649-54. https://doi.org/10.1016/j.ejcdt.2016.03.009

17. Bixler E, Vgontzas A, Have TT, Tyson K, Kales A. Effects of age on sleep apnea in men. Pneumologie. 1998;52(8):467-8.

18. Wosu AC, Vélez JC, Barbosa C, Andrade A, Frye M, Chen X, et al. The relationship between high risk for obstructive sleep apnea and general and central obesity: Findings from a sample of Chilean college students. ISRN Obes. 2014;2014:871681. https://doi.org/10.1155/2014/871681 PMid:24944841

19. Veloro LV, Sarte MA, Castañeda SS. Collar size as predictor of obstructive sleep apnea. Philipp J Otolaryngol Head Neck Surg. 2008;23(2):14-6. https://doi.org/10.32412/pjohns.v23i2.727

20. Paul D, Varma S, Ajith VV. Airway in Class I and Class II skeleta pattern: A computed tomography study. Contemp Clin Dent. 2015;6(3):293-8. https://doi.org/10.4103/0976-237x.161856 PMid:26321823 